\title{
Pembekalan tentang Digital Marketing Strategy bagi Pengurus dan Anggota Dekopinda Jakarta Utara
}

\author{
${ }^{1)}$ Tony Sitinjak, ${ }^{2)}$ Budi Berlinton Sitorus, ${ }^{3)}$ Martha Ayerza Esra, \\ ${ }^{4)}$ Elis Sondang Dasawaty, ${ }^{5)}$ Farida Komalasari
}

\author{
${ }^{1)}$ Program Studi Manajemen, Institut Bisnis \& Informatika Kwik Kian Gie, \\ tony.sitinjak@kwikkiangie.ac.id \\ ${ }^{2)}$ Program Studi Teknik Informatika, Institut Bisnis \& Informatika Kwik Kian Gie, \\ budi.sitorus@kwikkiangie.ac.id \\ ${ }^{3)}$ Program Studi Manajemen, Institut Bisnis \& Informatika Kwik Kian Gie, \\ martha.ayerza@kwikkiangie.ac.id \\ 4)Program Studi Sistem Informasi, Institut Bisnis \& Informatika Kwik Kian Gie, \\ elis.sondang@kwikkiangie.ac.id \\ ${ }^{5)}$ Program Studi Administrasi Bisnis, Universitas Presiden, \\ farida_k@president.ac.id
}

\begin{abstract}
ABSTRAK
Saat ini penguasaan terhadap digital marketing telah menjadi sebuah keharusan bagi para pelaku bisnis. Namun demikian masih banyak pihak yang belum menguasainya. Dalam rangka memberikan pembekalan dan pengayaan tentang digital marketing strategy, kegiatan Pengabdian kepada Masyarakat (PKM) ini dilaksanakan bekerjasama dengan Dekopinda Jakarta Utara. Diawali dengan perumusan masalah, dilanjutkan dengan perumusan materi dan penentuan bentuk kegiatan, PKM ini dilaksanakan pada tanggal 26 Juni 2021 dengan menggunakan platform online, karena berlangsung di tengah Pandemi Covid-19 dan pemberlakuan Peraturan Pembatasan Kegiatan Masyarakat (PPKM) Mikro di DKI Jakarta. Kegiatan ini diikuti oleh 35 peserta yang merupakan Pengurus dan Agggota Dekopinda Jakarta Utara. Materi yang disampaikan meliputi pengertian digital marketing, saluran digital marketing, internet marketing dan saluran utamanya, cara memulai digital marketing, strategi memilih media sosial sebagai sedia promosi, dan cara memilih marketplace bagi pemula. Setelah mengikuti kegiatan ini, peserta merasakan manfaat yang besar dan mengusulkan adanya kegiatan sejenis dengan topik yang berbeda. Topik yang diusulkan adalah kepemimpinan dan identifikasi peluang bisnis di masa pandemi.
\end{abstract}

Kata-kata Kunci: Digital Marketing, Strategy, Marketplace, Dekopinda Jakarta Utara

\begin{abstract}
Currently mastery of digital marketing has become a must for business people. However, there are still many parties who have not mastered it. In order to provide briefing and enrichment on digital marketing strategy, this community service activity (PKM) was carried out in collaboration with Dekopinda - North Jakarta. Starting with the formulation of the problem, followed by the formulation of the material and the determination of the form of activity, this PKM was carried out on June 26, 2021 using an online platform, because it took place in the midst of the Covid-19 Pandemic and the implementation of the PPKM Mikro in DKI Jakarta. This activity was attended by 35 participants who are the Managements and Members of Dekopinda - North Jakarta. The material presented includes the understanding of digital marketing, digital marketing channels, internet marketing and its main channels, how to start digital marketing, strategies for choosing social media as a promotional tool, and how to choose a marketplace for beginners. After participating in this activity, participants felt great benefits and suggested similar activities with different topics. The proposed topics are leadership and identification of business opportunities during a pandemic.
\end{abstract}

Keywords: Digital Marketing, Strategy, Marketplace, Dekopinda Jakarta Utara 


\section{PENDAHULUAN}

Koperasi di Indonesia, menurut Undang-undang No. 25 Tahun 1992, didefinisikan sebagai "badan usaha yang beranggotakan orang-seorang atau badan hukum koperasi dengan melandaskan kegiatannya berdasarkan prinsip-prinsip koperasi sekaligus sebagai gerakan ekonomi rakyat yang berdasar atas asas kekeluargaan" (UU No. 25 1992).

Koperasi di Indonesia telah dimulai sejak sebelum kemerdekaan Indonesia. Setelah kemerdekaan, untuk memperkuat koperasi, muncul gagasan dari para tokoh koperasi untuk memiliki satu wadah organisasi. Wadah tersebut adalah Sentral Organisasi Koperasi Rakyat Indonesia (SOKRI). Dalam perjalanannya, pada tahun 1968 SOKRI berubah menjadi Dewan Koperasi Indonesia (Dekopin) (Dekopin, 2021a).

Dekopin adalah organisasi tunggal gerakan koperasi Indonesia. Selain mempromosikan nilai-nilai dan prinsip-prinsip koperasi, Dekopin juga bertugas mewakili gerakan koperasi Indonesia dalam kegiatan di lingkup domestik maupun internasional. Tugas lainnya adalah menjadi mitra pemerintah dalam pengembangan koperasi di Indonesia (Dekopin, 2021a). Dekopin mempunyai struktur di tingkat pusat, provinsi (Dekopin Wilayah atau Dekopinwil), yang berjumlah 34, dan di tingkat kabupaten/kota (Dekopin Daerah atau Dekopinda) yang berjumlah 481 (Dekopin, 2021b).

Salah satu Dekopinda adalah Dekopinda Jakarta Utara. Berdasarkan analisis situasi dan diskusi dengan Pengurus dan Anggota Dekopinda Jakarta Utara, maka permasalahan yang dihadapi oleh Dekopinda Jakarta Utara adalah sebagai berikut:

1. Belum pernah dilakukan sosialisasi tentang digital marketing bagi Pengurus dan Anggota Dekopinda Jakarta Utara, yang sangat dibutuhkan di era bisnis saat ini.

2. Belum adanya pengayaan pengetahuan tentang perencanaan dan pengembangan digital marketing strategy bagi Pengurus dan Anggota Dekopinda Jakarta Utara.

Berdasarkan rumusan masalah tersebut maka dilakukan kegiatan Pengabdian kepada Masyarakat (PKM) dalam bentuk pembekalan kepada Pengurus dan Anggota Dekopinda Jakarta Utara tentang digital marketing strategy dan pengayaan materi dengan aplikasi Google Chrome dengan menggunakan salah satu media sosial yaitu facebook.

Oleh karena itu, tujuan dari PKM ini adalah (1) memberikan pembekalan kepada Pengurus dan Anggota Dekopinda Jakarta Utara; (2) memberikan pengayaan pengetahuan kepada Pengurus dan Anggota Dekopinda Jakarta Utra; tentang digital marketing strategy.

Manfaat PKM ini adalah (1) meningkatnya pengetahuan dan keterampilan para Pengurus dan Anggota Dekopinda Jakarta Utara tentang digital marketing strategy; (2) meningkatnya pengetahuan para Pengurus dan Anggota Dekopinda Jakarta Utara tentang 
kelebihan dan kekurangan dari digital marketing; (3) meluasnya jaringan kerjasama antar organisasi koperasi dan antara koperasi dengan institusi pendidikan.

\section{METODE PELAKSANAAN}

Kegiatan PKM ini dilaksanakan dengan tahapan aktivitas sebagai berikut:

1. Komunikasi antara Lembaga Penelitian dan Pengabdian Masyarakat (LPPM) Institut Bisnis dan Informatika Kwik Kian Gie (IBI-KKG) dengan Pengurus Dekopinda Jakarta Utara

Diawali dengan penerbitan surat tugas oleh LPPM IBI-KKG untuk tim pelaksana PKM, selanjutnya tim pelaksana berkoordinasi dengan Pengurus Dekopinda Jakarta Utara, khususnya yang bertanggung jawab terhadap pengembangan sumber daya manusia.

2. Perumusan Masalah

Tahap berikutnya adalah melakukan diskusi dan wawancara antara tim pelaksana dengan Pengurus Dekopinda Jakarta Utara tentang permasalahan yang dihadapi dan hal-hal yang diperlukan dalam pengembangan koperasi. Pada akhir tahap ini dapat dirumuskan permasalahan yang dihadapi sebagaimana telah dijelaskan pada bagian akhir Bab Pendahuluan di atas.

3. Perumusan Materi Kegiatan

Tahap berikutnya adalah perumusan materi yang akan diberikan. Berdasarkan diskusi yang dilakukan, maka ditetapkan tema kegiatan yaitu "Pembekalan Digital Marketing Strategy, khususnya Upaya untuk Memilih Marketplace sesuai Produk". Materi yang disampaikan meliputi: (1) pengertian digital marketing; (2) saluran digital marketing; (3) internet marketing; (4) saluran utama internet marketing (website, search marketing (Search Engine Optimization-SEO dan Paid Search Advertising-PSA), social media marketing, email marketing, mobile marketing, banner advertising); (5) cara memulai digital marketing; (6) strategi memilih media sosial sebagai sedia promosi; (7) cara memilih marketplace bagi pemula. Sumber utama materi yang disampaikan adalah buku Digital Marketing Concept (Muljono, 2018).

4. Perumusan Bentuk Kegiatan

Mengingat bahwa pada saat kegiatan ini berlangsung tengah terjadi Pandemi Covid-19 dan diberlakukannya PPKM Mikro di Wilayah DKI Jakarta, maka seluruh aktivitas dilakukan secara online. Aktivitas tersebut mencakup presentasi, ceramah, diskusi, tanya jawab, dan coaching yang dilakukan dengan platform online seminar.

5. Penetapan Jadwal Kegiatan

Berdasarkan kesepakatan antara tim pelaksana dan Pengurus Dekopinda Jakarta Utara, maka kegiatan dilaksanakan pada Sabtu, 26 Juni 2021. 
6. Pembuatan Brosur Kegiatan

Langkah berikutnya adalah membuat brosur kegiatan untuk keperluan promosi kegiatan dan rekrutmen peserta (lihat Gambar 1).
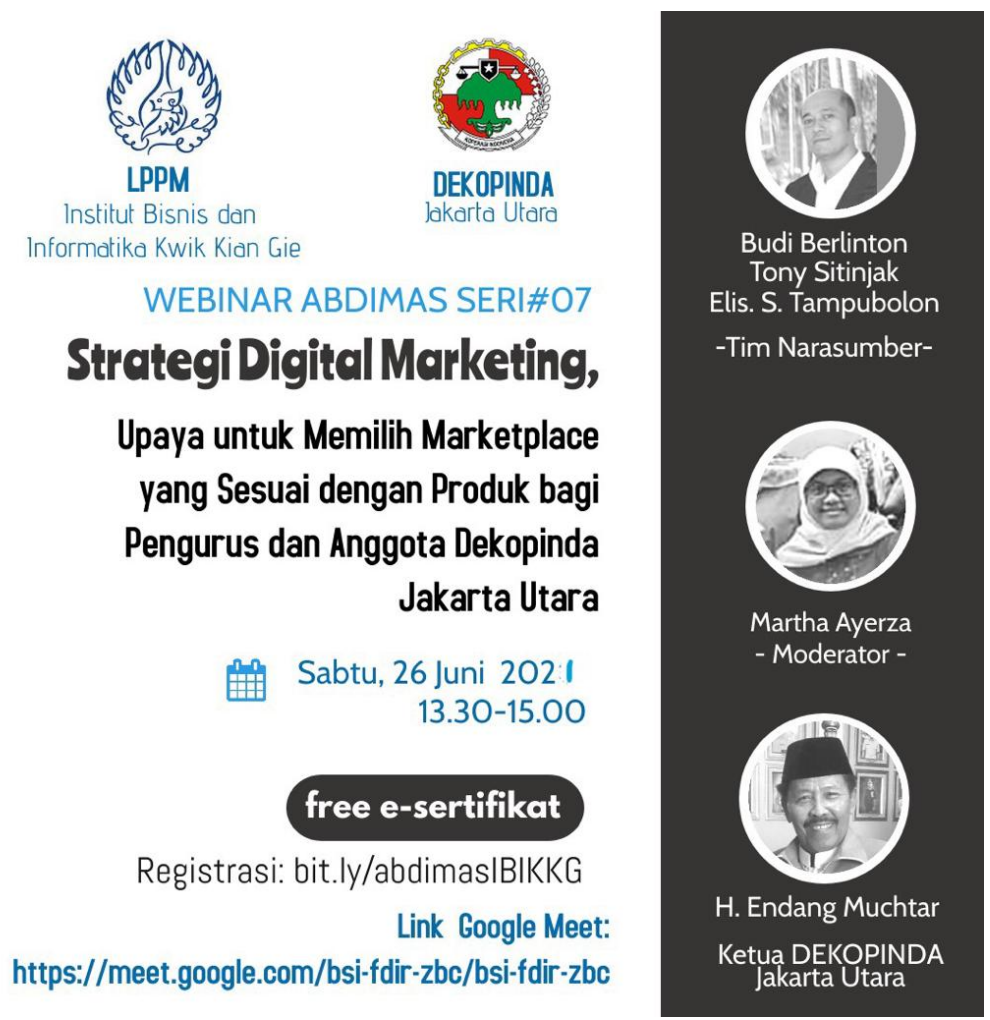

Gambar 1.

Brosur Kegiatan

7. Pelaksanaan Kegiatan

Kegiatan ini melibatkan para dosen sebagai nara sumber dan moderator. Di samping itu juga diundang seorang pembicara tamu, yaitu Sdr. Jayanti Sitorus, yang merupakan praktisi bisnis yang telah menerapkan digital marketing strategy dalam menjalankan bisnisnya. Jumlah peserta adalah 35 orang yang merupakan Pengurus dan Anggota Dekopinda Jakarta Utara (lihat Lampiran 1).

\section{HASIL DAN PEMBAHASAN}

\subsection{Gambaran Umum}

Secara umum, sejak persiapan hingga hari pelaksanaan, kegiatan berjalan secara lancer. Komunikasi yang terjalin antara LPPM-IBI KKG dengan Dekopinda Jakarta Utara telah membuka kesempatan adanya kerjasama antar dua lembaga. Komunikasi yang baik antara tim pelaksana dengan Pengurus Dekopinda Jakarta Utara telah membuka 
kesempatan diselenggarakannnya kegiatan PKM ini. Salah satu kunci sukses dari kegiatan ini adalah adanya peserta. Terbukti kerjasama ini telah berhasil diikuti oleh sejumlah 35 peserta.

Kerjasama yang baik antar anggota tim pelaksana yang ditunjukkan sejak awal kegiatan hingga kegiatan berjalan telah mengantarkan pada lancarnya kegiatan dan berlangsung secara sukses. Pembagian tugas dilakukan dengan baik, dalam hal siapa berperan sebagai apa dan melakukan apa. Tim pelaksana diperlukan untuk berperan sebagai nara sumber, moderartor, penulis laporan akhir dan anggota tambahan sebagai penulis publikasi kegiatan.

\subsection{Kegiatan Tim Pelaksana}

Tabel 1 menunjukkan tahapan kegiatan sejak penjajakan, persiapan hingga pelaksanaannya.

Tabel 1.

Jadwal Kegiatan Tim Pelaksana, 2021

\begin{tabular}{|c|l|c|c|c|c|}
\hline No. & \multicolumn{1}{|c|}{ Kegiatan } & Maret & April & Mei & Juni \\
\hline 1. & $\begin{array}{l}\text { Komunikasi LPPM-IBI KKG dengan } \\
\text { Dekopinda Jakarta Utara }\end{array}$ & XX & & & \\
\hline 2. & Perumusan Masalah & & $\mathrm{XX}$ & & \\
\hline 3. & Perumusan Materi & & $\mathrm{XX}$ & & \\
\hline 4. & Perumusan Bentuk Kegiatan & & $\mathrm{XX}$ & & \\
\hline 5. & Perumusan Jadwal & & $\mathrm{XX}$ & & \\
\hline 6. & Pembuatan Brosur & & & & $\mathrm{XX}$ \\
\hline 7. & Pelaksanaan & & & & \\
\hline
\end{tabular}

\subsection{Pelaksanaan Kegiatan}

Kegiatan PKM dilaksanakan pada tanggal 26 Juni 2021, dengan menggunakan platform Google-Meeting (lihat Gambar 2). Peserta sangat antusias mengikuti seluruh kegiatan. Hal ini terbukti dari banyaknya pertanyaan dan tanggapan melalui chat-room (lihat Gambar 3). Pada akhir acara, dilakukan penutupan acara oleh Pengurus Dekopinda Jakarta Utara. 


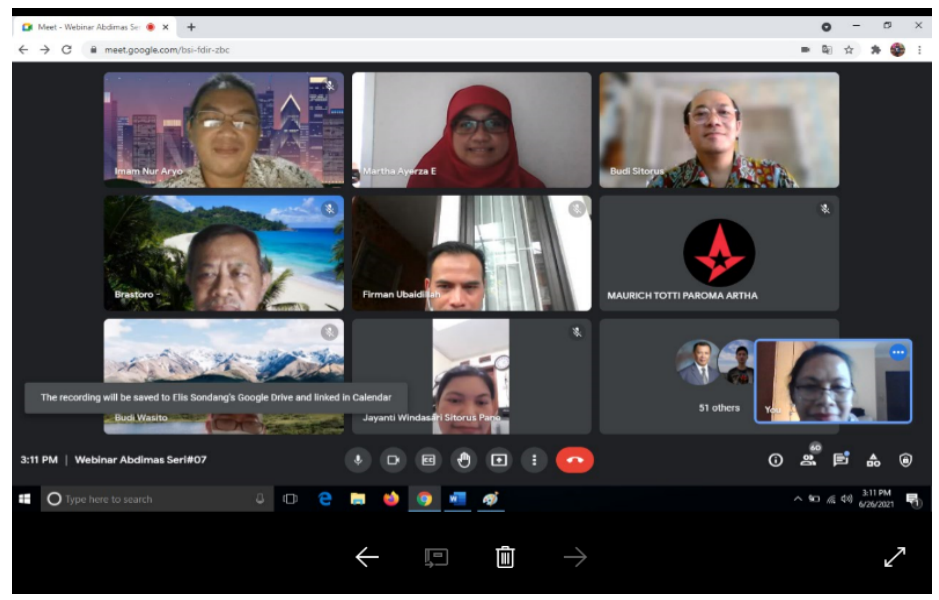

Gambar 2.

Foto Kegiatan melalui Google-Meeting

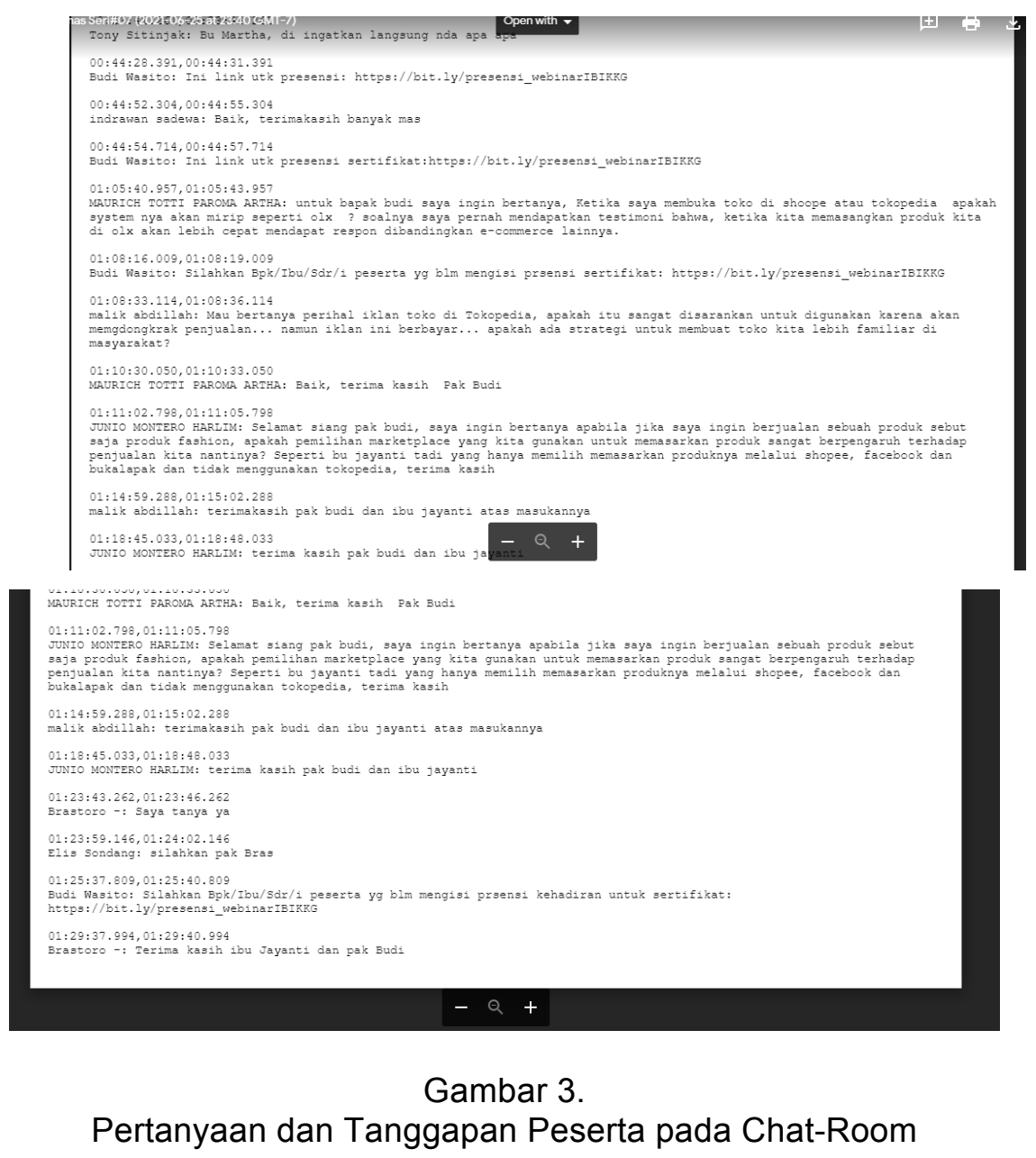

\subsection{Dampak Kegiatan}

Kegiatan ini berdampak pada peningkatan pemahaman peserta mengenai digital marketing strategy dalam upaya memilih marketplace yang sesuai dengan produk yang dihasilkan dan atau ditawarkan. Kegiatan diskusi dan coaching secara interaktif 
berlangsung dengan baik. Nara sumber yang terdiri dari dosen yang memiliki kompenetsi dalam bidangnya serta pembicara tamu yang merupakan seorang praktisi berpengalaman mampu menjawab seluruh pertanyaan peserta dan mampu menjadi mitra diskusi yang handal. Materi pembekalan dan pengayaan yang disampaikan dengan bahasa yang sederhana dapat dipahami dengan baik oleh peserta. Cara penyampaian yang sistematis mengakibatkan mudah diterimanya materi oleh peserta. Hal ini dibuktikan dengan banyaknya tanggapan, pertanyaan, dan harapan yang disampaikan oleh peserta (lihat kembali Gambar 3).

Pihak Dekopinda Jakarta Utara dapat menerima masukan dari narasumber bahwa pengurus koperasi harus menguasai digital marketing strategy karena bisnis masa depan tidak dapat lepas dari teknologi digital. Pertumbuhan penggunaan internet yang sangat cepat menuntut para pelaku bisnis, termasuk koperasi, untuk menguasai digital marketing.

Jumlah iklan digital telah mengalahkan iklan konvensional yang selama ini dilakukan melalui televisi dan jaringan televisi kabel. Peningkatan kegiatan pemasaran melalui digital multi-channel telah mengalahkan iklan konvensional. Iklan digital telah terbukti efektif meningkatkan brand awareness dan juga brand image perusahaan. Oleh karenanya, koperasi juga dituntut untuk meningkatkan penggunaan iklan digital. Penggunaan iklan digital dapat dilakukan tidak hanya oleh pelaku usaha besar, namun juga dapat dilakukan oleh pelaku usaha mikro, kecil dan menengah. Terbuka kesempatan yang lebar bagi koperasi dan anggota koperasi untuk mulai memanfaatkan teknologi digital dalam memasarkan produknya. Sekali lagi, penguasaan digital marketing bagi pengurus dan anggota koperasi menjadi sebuah keharusan.

Setelah mendapatkan materi pada PKM ini, peserta menyadari bahwa digital marketing adalah hal yang mudah dipelajari dan bermanfaat dalam pengembangan bisnis. Apalagi di saat Pandemi Covid-19, pemasaran secara online sangat diminati. Platform ini sangat tepat untuk menghindari aktivitas keluar rumah dan menghindari kerumunan.

Peserta menyadari bahwa pemasaran produk melalui marketplace dapat meningkatkan volume penjualan. Kuncinya adalah pada pemilihan marketplace yang sesuai dengan produk yang ditawarkan. Kegiatan PKM ini dirasakan sangat berguna bagi para pelaku usaha dalam menentukan marketplace atas produknya.

\section{KESIMPULAN}

Kegiatan PKM ini berlangsung dengan baik, dengan jumlah peserta sebanyak 35 orang. Para peserta terlihat sungguh-sungguh memperhatikan materi yang diberikan dan sangat antusias mengikuti acara diskusi, tanya jawab, dan coaching. Kasus bisnis yang 
berkaitan dengan pemasaran ditanyakan kepada para nara sumber untuk mendapatkan alternatif-alternatif solusi.

Peserta menyatakan bahwa kegiatan ini sangat berguna dan memberi bekal kepada mereka untuk bisa menerapkan digital marketing, termasuk penentuan marketplace yang tepat atas produk yang dihasilkannya. Kegiatan semacam ini diharapkan dapat dilakukan kembali dengan materi yang berbeda. Materi yang diusulkan adalah tentang kepemimpinan dan identifikasi peluang bisnis di masa pandemi. Oleh karena itu, kerjasana antara lembaga pendidikan tinggi dengan lembaga bisnis sangat diperlukan karena terbukti memberikan manfaat bagi kedua belah pihak.

\section{REFERENSI}

Dekopin. 2021a. Sejarah Koperasi Indonesia. Diunduh dari: https://dekopin.coop/dekopin/kilas-balik/

Dekopin 2021b. Nama dan Alamat Dekopinda. Diunduh dari: https://dekopin.coop/dekopinda/

Dewan Perwakilan Rakyat - Republik Indonesia. 2021. Undang-undang Nomor 25 Tahun 1992 tentang Perkoperasian. Diunduh dari:

https://www.dpr.go.id/dokjdih/document/uu/783.pdf

Muljono, R.K. 2018. Digital Marketing Concept. Jakarta: Gramedia Pustaka Utama.

Lampiran 1.

Peserta Kegiatan

\begin{tabular}{|c|c|c|}
\hline & 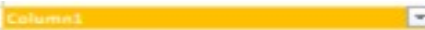 & jestumnz \\
\hline No & Nama mosexta & Asea insmius \\
\hline 1 & Anoeline & KWWIK KJen Ge \\
\hline 2 & Renoy Sot awen & Kiwik kien Ge \\
\hline 3 & Moidr Aunore Cacsalla & Iel Kwik Kian Ge \\
\hline 4 & Snalsabila Ser & IEAKKG \\
\hline 5 & Junio Monteno Hollim & Kw/k KIen Ge School ar lusiness \\
\hline 6 & Aones Pometased & Instout Bisnis den intommabka kwik kien qie \\
\hline 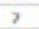 & Orrestella Agatra & IeAKKG \\
\hline$s$ & Juritence Morciua Um & 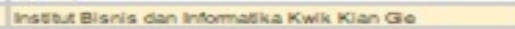 \\
\hline 9 & miman Veleta & 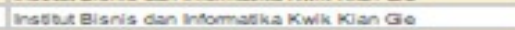 \\
\hline 10 & Fach12a Bayu Ueama & KWik KIen Ge \\
\hline 11 & Rainenda Lutharayen & 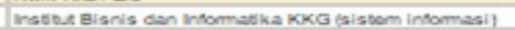 \\
\hline 12 & Estor ssoetent & KWRK KLAN GE SCHOO OF RUSANESS \\
\hline 13 & Groce Ellsa Motant & IEIIIKKG \\
\hline 14 & Maulen Tom Peroma & Instros Bisnis can intomedk ka Kwlk KIen Ge \\
\hline is & Vincent & KWWlk KIen Ge School ar lusiness \\
\hline 16 & Fonor Setrawan & Kwik kien Ge \\
\hline 17 & Sancaem Mala & IEIIKKG \\
\hline 18 & Valoncia Alexandra & KWik Kien Ge School of elusiness \\
\hline 19 & Androw Ondsbogher Kosasin & Kwik KIan Ge School or leusiness \\
\hline 20 & Oivia Sunerd Samsico & Ie:ll KWik KJen Ge \\
\hline 21 & Al Sentava & Kwik Klen Go \\
\hline 22 & Sseverny Vilensia Chander & Kiwlk KIen Ge School of Rusiness \\
\hline 23 & Folicia Jonatren & IEIIIKKG \\
\hline 24 & Valencia & KWXK KIAN GE SCHOQ OF BUSINESS \\
\hline 25 & mbono Mulia Goutama & KWik KIen Ge \\
\hline 26 & ewoene byen los & ibikkg \\
\hline 27 & Mcheel Jonothen Sertawen & 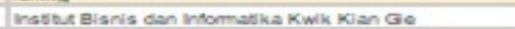 \\
\hline 28 & Jond Fomendo Laurentivs & Instout KW/K KIan Ge \\
\hline 29 & Edor Winerso S E MSI MEA PND MK CA & UNJANII \\
\hline 30 & Demes peskalis pulerto & Ielikkg \\
\hline 31 & 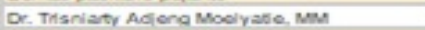 & Universitas Munemmesiyan Palembere \\
\hline 32 & Yuaro Hokimen & Universitas Thainents \\
\hline 33 & Meny Kalvenet & KWR KUAN GE SCHOO OF BUSWESS \\
\hline 34 & Sancoem Mala & EIIIKKG \\
\hline 35 & Roolly Humblana & IEI KKG \\
\hline
\end{tabular}

